\title{
The Relevance of Small Airway Dysfunction in Asthma with Nocturnal Symptoms
}

\author{
Mustafa Abdo, (iD) \\ Frederik Trinkmann, (D) 2,3 Anne- \\ Marie Kirsten, ${ }^{4}$ Heike Biller, \\ Frauke Pedersen, ${ }^{1,4}$ Benjamin Waschki, \\ Erika Von Mutius, ${ }^{5}$ Matthias Kopp, ${ }^{6,7}$ \\ Gesine Hansen, ${ }^{8}$ Klaus F Rabe, \\ Thomas Bahmer, ${ }^{1,9, *}$ Henrik Watz ${ }^{4, *}$ \\ On behalf of the ALLIANCE study group
}

'LungenClinic Grosshansdorf, Airway Research Center North (ARCN), German Center for Lung Research (DZL), Grosshansdorf, Germany; ${ }^{2}$ Department of Pneumology and Critical Care Medicine, Thoraxklinik, University of Heidelberg, Translational Lung Research Center Heidelberg (TLRC), German Center for Lung Research (DZL), Heidelberg, Germany; ${ }^{3}$ Department of Biomedical Informatics, Heinrich-Lanz-Center, University Medical Center Mannheim, Heidelberg University, Heidelberg, Germany; ${ }^{4}$ Pulmonary Research Institute at the LungenClinic Grosshansdorf, Airway Research Center North (ARCN), German Center for Lung Research (DZL), Grosshansdorf, Germany; ${ }^{5} \mathrm{Dr}$ von Hauner Children's Hospital, Ludwig Maximilians University of Munich, Comprehensive Pneumology Center Munich, German Center for Lung Research (DZL), and Institute of Asthma and Allergy Prevention, Helmholtz Centre, Both Munich, Germany; ${ }^{6}$ Department of Pediatric Respiratory Medicine, Inselspital, University Children's Hospital of Bern, University of Bern, Bern, Switzerland; ${ }^{7}$ Division of Pediatric Pneumology \& Allergology, University Hospital Schleswig-Holstein-Campus Luebeck, Airway Research Center North (ARCN), German Center for Lung Research (DZL), Luebeck, Germany; ${ }^{8}$ Department of Paediatric Pneumology, Allergology and Neonatology, Hannover Medical School, Biomedical Research in Endstage and Obstructive Lung Disease (BREATH), German Center for Lung Research (DZL), Hannover, Germany; ${ }^{9}$ University Hospital Schleswig-HolsteinCampus Kiel, department for Internal Medicine I, Airway Research Center North (ARCN), German Center for Lung Research (DZL), Kiel, Germany

*These authors contributed equally to this work

Correspondence: Mustafa Abdo

LungenClinic Grosshansdorf, Airway Research Center North (ARCN), German Center for

Lung Research (DZL), Wöhrendamm 80

Grosshansdorf, 22927, Germany

Tel +494I02 60I 24I2

Email m.abdo@lungenclinic.de
Rationale: Small airway dysfunction (SAD) is a frequent feature of asthma that has been linked to disease severity and poor symptom control. However, little is known about the role of SAD in nocturnal asthma.

Objective: To study the association between the severity of SAD and frequency of nocturnal symptoms compared to conventional lung function testing.

Methods: We assessed the frequency of self-reported nocturnal symptoms through the asthma control test. We studied the impact of nocturnal asthma using the Asthma Quality of Life Questionnaire (AQLQ) and the Multidimensional Fatigue Inventory (MFI-20). We assessed the lung function using spirometry, body plethysmography, impulse oscillometry, single and multiple inert gas washout and measured markers of T2-inflammation (blood and sputum eosinophils; fractional exhaled nitric oxide (FeNo)). We stratified the patients according to the presence and frequency of nocturnal asthma.

Results: A total of 166 asthma patients were enrolled in the analysis. Eighty-seven patients $(52 \%)$ reported to have nocturnal symptoms at least once in the last four weeks. The odds ratio of nocturnal asthma correlated with the severity of all non-spirometric measures of SAD, yet neither with airflow obstruction (FEV1 and FEV/FVC) nor with large airway resistance $(\mathrm{R} 20)$. Patients with frequent nocturnal asthma $(n=29)$ had a numerical increase of T2 markers and more severe SAD, as indicated by all non-spirometric measures of SAD (all p-values $<0.05$ ), worse overall asthma control, increased fatigue and reduced quality of life (all p-values $<0.01)$ compared to patients with infrequent nocturnal asthma $(\mathrm{n}=58)$ or patients without nocturnal asthma $(\mathrm{n}=79)$. We identified 63 patients without airflow obstruction, nearly $43 \%$ of them $(n=27)$ had nocturnal asthma. In this subgroup, only markers of air trapping and ventilation heterogeneity were significantly elevated and correlated with the frequency of nocturnal symptoms: LCI (Spearman's coefficient $=-0.42, p<$ $0.001), \mathrm{RV} \%(-0.32, \mathrm{p}=0.02)$.

Conclusion: SAD is closely associated to asthma with nocturnal symptoms. Spirometry might underestimate the broad spectrum of distal lung function impairments in this population of patients.

Keywords: small airway dysfunction, nocturnal asthma, ventilation heterogeneity, air trapping

\section{Background}

Asthma is a heterogeneous airway disease that is characterized by variable clinical presentation. ${ }^{1}$ Nocturnal asthma, defined as nighttime worsening of asthma symptoms and lung function, is a common disease presentation that affects nearly two thirds of the patients. ${ }^{2,3}$ Nocturnal asthma is an important indicator of poor symptom control and is associated with impaired quality of life and higher rates of 
asthma morbidity and mortality. ${ }^{4}$ Previous studies have demonstrated several potential mechanisms that contribute to the nocturnal worsening of asthma. This includes an exaggerated circadian variation in the lung function, ${ }^{5}$ indicated by a decline in the expiratory airflow ${ }^{6}$ and an increase in small airway resistance ${ }^{7}$ which might be triggered by an augmented eosinophil inflammation of the small airways at nighttime. ${ }^{8}$ Collectively, these findings point towards an overnight increase in small airway inflammation and small airway resistance as the potential determinant of small airway dysfunction (SAD) in nocturnal asthma. SAD is a highly prevalent feature of asthma that has been frequently linked to disease severity and physical inactivity. ${ }^{9,10}$ Accordingly, it is reasonable to hypothesize that the assessment of small airway function might be a suitable approach to identify, monitor or even guide treatment in asthma patients with nocturnal symptoms. However, data that correlate measures of small airway function, performed at daytime as a part of the routine clinical practice, with the presence and frequency of nocturnal symptoms are limited. Furthermore, while the routine assessment of lung function in asthma relies mostly on spirometry only, little is known about the feasibility of small airway function measures in the diagnosis of symptomatic asthma patients with nocturnal asthma, who have normal spirometry.

In this context, we studied the association of broad spectrum small airway function measures with the presence and frequency of nocturnal symptoms compared to conventional spirometry.

\section{Methods}

\section{Study Design}

Eligible subjects were adults with asthma who were recruited to the multicenter prospective longitudinal All Age Asthma Cohort (ALLIANCE), a cohort of pediatric and adult patients with asthma in Germany, initiated by the German Centre for Lung Research (DZL). The study was approved according to the Declaration of Helsinki by a local ethics committee at the medical school Luebeck (Az.21-215) and is registered at clinicaltrials.gov (adult arm: NCT02419274). All subjects provided written informed consent prior to enrollment. Detailed information regarding the ALLIANCE recruitment, inclusion and exclusion criteria was described previously. ${ }^{11}$ This study is a cross-sectional analysis of a cohort of patients who attended the second study visit at one study site, the
LungenClinic Grosshansdorf, where the required broad lung function assessment is available. All 166 asthma patients who attended the study visit were included. Regular study visits take place when patients have rather a stable phase of their disease in the absence of acute exacerbation or respiratory tract infection within four weeks prior to the study visit.

To evaluate night symptoms, we used the third question from the Asthma Control Test (ACT) which has been validated to evaluate asthma control in adults. ${ }^{12}$ Patients were asked how often their asthma symptoms did wake them up in the night in the last four weeks, or whether they got up unusually early in the morning. Accordingly, patients were classified into three groups: the first group included patients who did not experience night symptoms in the last four weeks. The second group exhibited infrequent nocturnal asthma, and included patients who had nighttime symptoms only one to two times per month. The last group was defined as frequent nocturnal asthma and included patients who had night symptoms at least once per week. To study the impact of nocturnal asthma we applied the Asthma Quality of Life Questionnaire $(\mathrm{AQLQ})^{13}$ and the Multidimensional Fatigue Inventory (MFI-20). ${ }^{14}$

\section{Lung Physiology Characteristics}

We performed body plethysmography, impulse oscillometry (IOS), single and multiple breath washout (SBW, MBW), followed by forced spirometry in accordance with current ERS recommendations. ${ }^{15-18}$ All lung function measures were performed in the morning and patients had their controller medications as usual. We studied airflow obstruction using predicted values of FEV1 and its ratio to the forced vital capacity (FVC). Reference equations for lung volumes and forced flows were as provided by the European Community for Coal and Steel. ${ }^{19}$ Airflow obstruction was defined as FEV1/FVC below the lower limit of normal (LLN). ${ }^{20}$ Measures of small airway function were: mean forced expiratory flow at $50 \%$ and between $25 \%$ and $75 \%$ of the forced vital capacity (FEF50\%, FEF25-75\%) from spirometry, residual lung volume (RV\%) and its ratio to total lung capacity (RV/ TLC) and the specific effective airway resistance (sReff\%) from body plethysmography, small airway resistance $(\mathrm{R} 5 \mathrm{~Hz}-20 \mathrm{~Hz}, \mathrm{kPa} / \mathrm{L} / \mathrm{s}))$ and lung reactance at $5 \mathrm{~Hz}(\mathrm{XHz}$, $\mathrm{kPa} / \mathrm{L} / \mathrm{s}$ ) from IOS. Additionally, we included markers of ventilation heterogeneity; the Phase III slope (delta $\mathrm{N}_{2} /$ ) derived from $\mathrm{N}_{2}$ SBW and the lung clearance index (LCI) 
measured by MBW test. We correlated the severity of lung function impairments, by using percentile cutoffs of lung function measures, with the incidence of nocturnal symptoms.

\section{Type-2 Markers of Airway Inflammation}

We measured eosinophils in induced sputum as previously described, ${ }^{21,22}$ fractional exhaled nitric oxide (FeNO), ${ }^{23}$ and blood eosinophils.

\section{Statistical Analysis}

We studied the odds of having nocturnal asthma in correlation to lung function measures using the Fisher's exact test. To determine the statistical significance of differences in clinical characteristics, lung function measures and biomarkers between the study groups we used the analysis of variance (ANOVA) test, Fisher's exact test, Kruskal rank test and for the post hoc analysis the Tukey's test or Dunn's test. Spearman's rank correlation was used to test for statistical dependence between two variables. We also performed a principle component analysis (PCA) in order to observe correlations between different lung function measures and the symptomatic presentation of asthma, including nighttime symptoms, based on the five components of the ACT score.

Statistical analyses were performed using $\mathrm{R}$ (version 3.6.2; R Foundation, Vienna, Austria). An alpha error of less than $5 \%$ was considered statistically significant.

\section{Results}

Detailed clinical and lung physiology characteristics of the 166 asthma patients are given in Table 1. More than half of the patients $(\mathrm{n}=87 ; 52 \%)$ reported to have nocturnal symptoms in the previous four weeks. The association of the severity of lung function impairment, ie airflow obstruction, increased small airway resistance, air trapping and ventilation heterogeneity, with the odds of having nocturnal asthma is presented in Figure 1 and in the Online Supplementary. We found that the odds of having nocturnal symptoms did not increase with the increase in airflow obstruction as indicated by FEV1 and FEV1/FVC. Even in patients with the most severe airflow obstruction and values below the 10th percentiles, ie FEV1 $<51 \%$ and FEV1/FVC $<47 \%$, no statistically significant increase in the odds of nocturnal symptoms could be observed (Figure 1A). Likewise, the increase of large airways resistance (R20) did not increase the odds of nocturnal asthma (Figure 1A). We also found no significant correlation
Table I Patients' Clinical Characteristics

\begin{tabular}{|c|c|}
\hline $\mathbf{n}$ & 166 \\
\hline Age, years & $52(45-64)$ \\
\hline Sex, \% male & 56 \\
\hline BMI, kg/m² & $26.8(23.9-30.0)$ \\
\hline Current smokers, \% & 9 \\
\hline Smoking history *, \% & 22 \\
\hline Maintenance ICS use,\% & 89 \\
\hline Maintenance ICS use combined with LABA, \% & 81 \\
\hline ICS dose, $\mu g$ & $500(250-1000)$ \\
\hline LAMA use,\% & 22 \\
\hline Maintenance OCS use,\% & 22 \\
\hline Biological therapy, \% & 6 \\
\hline Blood eosinophils / $\mu \mathrm{L}$ & $230(130-380)$ \\
\hline Sputum eosinophils, \% & I.7 (0.4-5.9) \\
\hline FeNo, ppb & $23(15-33)$ \\
\hline FEVI, \% & $84(67-96)$ \\
\hline FEVI/FVC, \% & $65(56-72)$ \\
\hline FEF50, \% & $48(29-7 I)$ \\
\hline FEF25-75, \% & $47(27-66)$ \\
\hline $\mathrm{R} 20, \mathrm{kPa} / \mathrm{L} / \mathrm{s}$ & $34(29-42)$ \\
\hline $\mathrm{R} 5-20, \mathrm{kPa} / \mathrm{L} / \mathrm{s}$ & $0.11(0.06-0.19)$ \\
\hline$\times 5 \mathrm{~Hz}, \mathrm{kPa} / \mathrm{L} / \mathrm{s}$ & $-0.14(-0.10-0.21)$ \\
\hline $\mathrm{RV}, \%$ & $128(|||-| 5 \mid)$ \\
\hline RV/TLC, \% & $41(35-48)$ \\
\hline sReff, \% & $107(83-169)$ \\
\hline $\mathrm{LCl}$ & $6.7(5.9-7.60)$ \\
\hline $\mathrm{N}_{2}$ Delta/l & $2.1(1.5-3.4)$ \\
\hline
\end{tabular}

Note: Values are presented in percentage or median and IQR.

Abbreviations: BMI, body mass index; ICS, inhaled corticosteroids; LABA, longacting beta-2-agonists; LAMA, long-acting muscarinic receptor antagonists; ICS dose, fluticasone equivalent; OCS, oral corticosteroids; FeNO, fractional exhaled nitric oxide; FEVI, forced expiratory volume in first second; FVC, forced vital capacity; FEF50\% and FEF25-75, mean forced expiratory flow at $50 \%$ and between $25 \%$ and $75 \%$ of the forced vital capacity; R20, proximal airway resistance at $20 \mathrm{~Hz}$; R5-20, small airway resistance (total lung resistance - large airway resistance); X5, lung reactance at $5 \mathrm{~Hz}$; RV, residual volume; TLC, total lung capacity; sReff, specific effective airway resistance; $\mathrm{LCl}$, lung clearance index from multiple breath washout, delta; N2, the slope of phase III nitrogen single-breath washout. Smoking history $\geq$ 10 pack years.

between spirometric measures of distal airways function (FEF50\%, FEF25-75\%) and the odds for nocturnal asthma except for patients with mid-expiratory flow obstruction who had FEF25-75 values below the 75th percentile, as these patients showed nearly a three-fold increase in the odds of nocturnal asthma (Figure 1B). By contrast, more severe SAD, indicated by all non-spirometric measures of small airway function was associated with higher odds of nocturnal asthma. This applied to the increase in small airway resistance (R5-20, sReff), increased air trapping (RV/TLC), decreased lung elasticity (X5Hz) and increased ventilation heterogeneity (delta $\mathrm{N}_{2}$ and LCI), as we observed higher odds of nocturnal asthma at cutoff values 


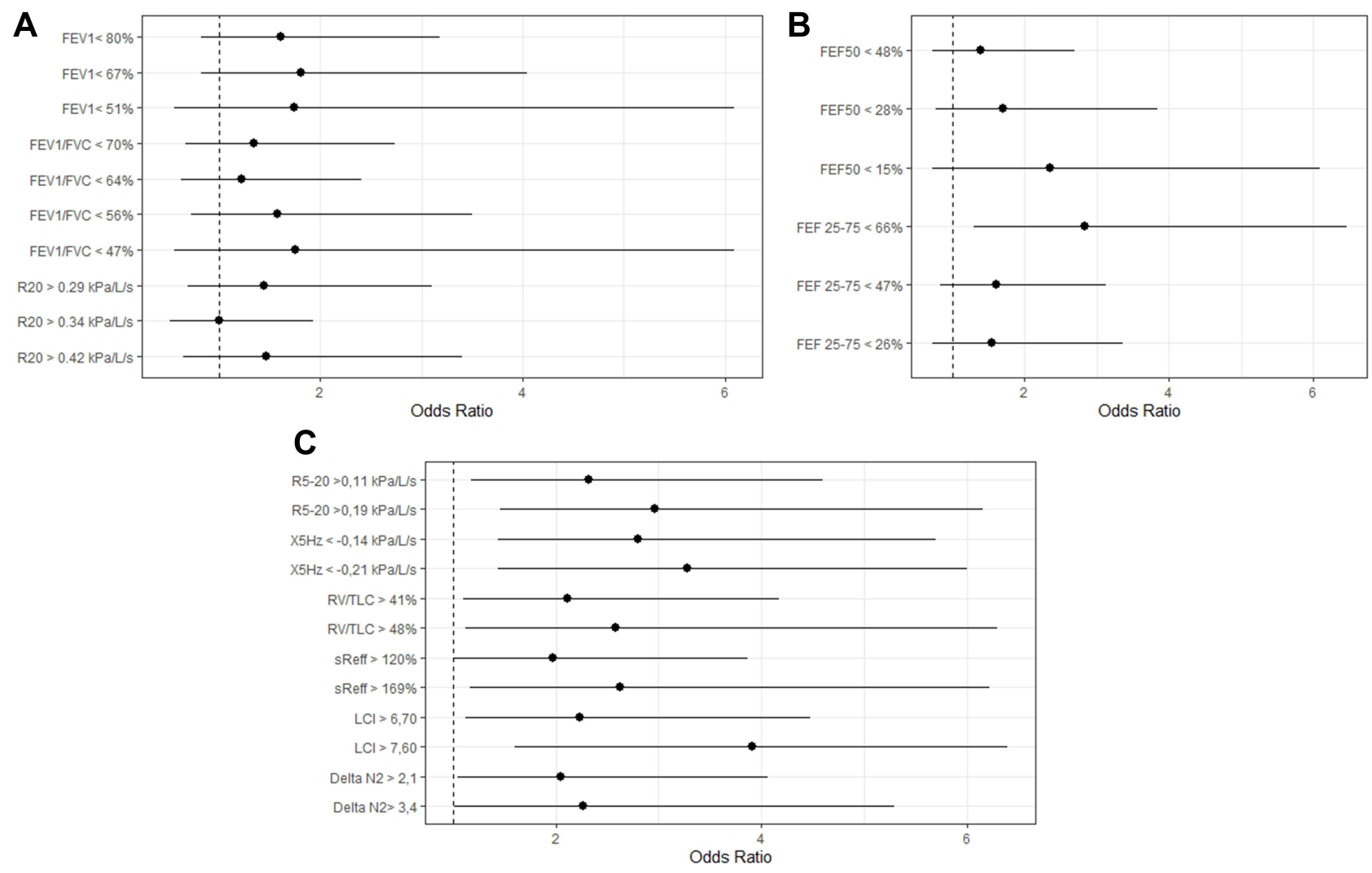

Figure I Odds ratio of nocturnal symptoms based on the severity of lung function impairment: Odds of having nocturnal asthma in regard to severity of central airflow obstruction (A), spirometric measures of small airway function (B) and non-spirometric measures of small airway function (C). OR with lower and upper borders of $95 \% \mathrm{Cl}$ of each measure are outlined in the Online Supplementary. Cutoff values of FEVI and FEV/FVC were determined at lower limit of normal, the 50th, 25th, and I0th percentiles. For FEF25-75 and FEF50 cutoff values were 75th, 50th, and 10th percentiles, where the 10th percentile indicates more severe large and mid-expiratory airflow obstruction. Cutoff values for R5-20, X5Hz, RV/TLC, sReff, delta N2 and LCl were at the 50th and 75th percentiles, where the 75th percentile indicates more severe SAD. Abbreviations: FEVI, forced expiratory volume in first second; FVC, forced vital capacity; FEF50\% and FEF $25-75$, mean forced expiratory flow at $50 \%$ and between $25 \%$ and $75 \%$ of the forced vital capacity; R20, proximal airway resistance at $20 \mathrm{~Hz}$; R5-20, small airway resistance (total lung resistance - large airway resistance); X5, lung reactance at $5 \mathrm{~Hz}$; RV, residual volume; TLC, total lung capacity; sReff, specific effective airway resistance; LCl, lung clearance index from multiple breath washout, delta; N2, the slope of phase III nitrogen single-breath washout.

at the 75th percentile, compared to lower cutoff values at the 50th percentile of each of these lung function measures, Figure 1C.

Further, two thirds of patients with nocturnal asthma had infrequent nocturnal symptoms $(n=58)$ with a remaining 29 patients who reported to have frequent nocturnal symptoms. Between these groups of patients, we observed no significant differences with respect to age, sex, BMI or smoking habits (Table 2). Furthermore, we found that both frequent and infrequent nocturnal asthma patients had higher doses of inhaled corticosteroids and a higher proportion of patients with regular oral corticosteroids intake, compared to patients without nocturnal asthma. We also found a numerical increase of Type- 2 inflammation markers (ie blood and sputum eosinophils, FeNO) in patients with frequent nocturnal asthma, yet without statistical significance (Table 2).
While measures of large airway obstruction (FEV1, FEV1/FVC and R20) were similar across these groups, all non-spirometric measures of small airway function indicated more severe small airway dysfunction in patients with frequent nocturnal asthma compared to patients with infrequent nocturnal asthma or patients without nocturnal (Table 2). Accordingly, patients with frequent nocturnal asthma also had poor overall asthma control, increased fatigue, and subsequently, reduced quality of life (Table 2).

Moreover, we identified 63 patients (mean age, $52 \pm 14$ years; $59 \%$ male; mean BMI, $27.1 \pm 4.7 \mathrm{~kg} / \mathrm{m}^{2}$ ) who had no airflow obstruction (FEV1/FVC $>$ LLN). Despite this, nearly $43 \%$ of them $(n=27)$ had nocturnal asthma and $37 \%$ even had frequent nocturnal asthma $(n=10)$. In this subgroup of patients without airflow obstruction, patients with nocturnal asthma showed no significant differences from patients without nocturnal asthma with regard to confounders: age (51.6 \pm 13 vs $53.8 \pm 14$, years), BMI 
Table 2 Clinical and Lung Physiology Characteristics of Asthma Patients According to the Frequency of Nocturnal Symptoms

\begin{tabular}{|c|c|c|c|c|}
\hline Parameter & No NA $(n=79)$ & Infrequent NA $(n=58)$ & Frequent NA $(n=29)$ & P-value \\
\hline Age, years & $51(43-63)$ & $54(46-63)$ & $58(49-67)$ & 0.32 \\
\hline Sex, \% male & 51 & 55 & 72 & 0.12 \\
\hline BMI (kg/m2) & $25.9(23.8-28.9)$ & $27.8(24.2-30.9)$ & $26.3(24.4-29.0)$ & 0.18 \\
\hline Current smokers,\% & 5 & 3 & 10 & 1.0 \\
\hline Smoking history*, \% & 22 & 22 & 27 & 0.71 \\
\hline Maintenance ICS use, \% & 88 & 90 & 90 & 0.34 \\
\hline ICS dose, $\mu \mathrm{g}$ & $400(250-775)$ & $750(287-1000)$ & $600(500-1000)$ & 0.004 \\
\hline Maintenance ICS/LABA, \% & 77 & 84 & 88 & 0.48 \\
\hline LAMA use, $\%$ & 16 & 27 & 24 & 0.28 \\
\hline Maintenance OCS use, \% & 16 & 27 & 38 & 0.063 \\
\hline Biological therapy; \% & 5 & 8 & 6 & $0.7 \mathrm{I}$ \\
\hline FeNO, ppb & $23(14-33)$ & $22(|5-3|)$ & $29(17-67)$ & 0.22 \\
\hline Blood eosinophils, / $\mu \mathrm{L}$ & $210(130-365)$ & $220(120-295)$ & $320(200-450)$ & 0.14 \\
\hline Sputum eosinophil count \% & $\mathrm{I} .5(0.5-5.1)$ & $0.9(0.4-4.2)$ & $4.0(1.3-9.0)$ & 0.24 \\
\hline $\mathrm{FEV}_{1}, \%$ & $85(73-104)$ & $81(64-92)$ & $81(65-91)$ & 0.071 \\
\hline $\mathrm{FEV}_{1} / \mathrm{FVC}$ & $65(58-72)$ & $63(53-73)$ & $62(52-70)$ & 0.32 \\
\hline $\mathrm{R}_{2 \mathrm{OHz}}, \mathrm{KPa} / \mathrm{l} / \mathrm{s}$ & $34(29-42)$ & $34(29-4 I)$ & $39(30-46)$ & 0.35 \\
\hline $\mathrm{FEF}_{25-75, \%}$ & $53(30-76)$ & $46(24-6 I)$ & $41(27-56)$ & 0.12 \\
\hline $\mathrm{FEF}_{50}, \%$ & $53(34-76)$ & $48(24-69)$ & $41(23-56)$ & 0.15 \\
\hline RV/TLC, \% & $39(33-45)$ & $42(36-49)$ & $43(38-58)$ & 0.016 \\
\hline $\mathrm{RV}, \%$ & $120(109-144)$ & $128(115-152)$ & $132(122-158)$ & 0.072 \\
\hline sReff\% & $100(79-139)$ & $128(1 \mid 5-152)$ & | $35(97-2||)$ & 0.002 \\
\hline $\mathrm{R}_{5 \mathrm{~Hz}}, \mathrm{KPa} / \mathrm{l} / \mathrm{s}$ & $0.46(0.35-0.52)$ & $0.45(0.36-0.62)$ & $0.55(0.4 I-0.69)$ & 0.03 \\
\hline $\mathrm{R}_{5-2 \mathrm{OHz}}, \mathrm{KPa} / \mathrm{l} / \mathrm{s}$ & $0.09(0.06-0.14)$ & $0.13(0.06-0.22)$ & $0.16(0.09-0.24)$ & 0.009 \\
\hline $\mathrm{X}_{5 \mathrm{~Hz}}, \mathrm{kPa} / \mathrm{L}$ & $-0.12(-0.16,-0.1)$ & $-0.16(-0.25,-0.10)$ & $-0.20(-0.30,-0.13)$ & 0.004 \\
\hline N2 Delta /I & $2.0(1.4-2.9)$ & $2.5(1.57-3.87)$ & $2.9(1.6-4.9)$ & 0.03 \\
\hline $\mathrm{LCl}$ & $6.4(5.6-6.8)$ & $6.9(6.1-8.0)$ & $7.3(6.4-8.2)$ & $<0.001$ \\
\hline ACT score & $22(19-24)$ & $17(13-20)$ & $13(9-16)$ & $<0.001$ \\
\hline AQLQ mean score & $5.9(5.2-6.5)$ & $4.7(4.0-5.6)$ & $3.7(2.9-4.7)$ & $<0.001$ \\
\hline MFI-20 & $39(29-50)$ & $43(35-58)$ & $54(48-64)$ & $<0.001$ \\
\hline
\end{tabular}

Note: Values are presented in percentage or median and IQR.

Abbreviations: NA, nocturnal asthma; BMI, body mass index; ICS, inhaled corticosteroids; LABA, long-acting beta-2-agonists; LAMA, long-acting muscarinic receptor antagonists; ICS dose, fluticasone equivalent; OCS, oral corticosteroids; FeNO, fractional exhaled nitric oxide; FEVI, forced expiratory volume in first second; FVC, forced vital capacity; FEF50\% and FEF25-75, mean forced expiratory flow at $50 \%$ and between $25 \%$ and $75 \%$ of the forced vital capacity; R20, proximal airway resistance at $20 \mathrm{~Hz}$; R5-20, small airway resistance (total lung resistance - large airway resistance); X5, lung reactance at $5 \mathrm{~Hz}$; RV, residual volume; TLC, total lung capacity; sReff, specific effective airway resistance; LCl, lung clearance index from multiple breath washout; delta N2, the slope of phase III nitrogen single-breath washout; ACT, asthma control test; AQLQ, asthma quality of life questionnaire; MFI-20, multidimensional fatigue inventory, smoking history with $\geq 10$ pack years.

$\left(27.3 \pm 4.8\right.$ vs $\left.27.0 \pm 4.7, \mathrm{~kg} / \mathrm{m}^{2}\right)$, or markers of $\mathrm{T} 2-$ inflammation: sputum eosinophils ( $4.9 \pm 12$ vs $5.0 \pm 10, \%)$, blood eosinophils $(260 \pm 200$ vs $250 \pm 160$, / $\mu \mathrm{L})$, FeNO (38 \pm 41 vs $24 \pm 18, \mathrm{ppb}$ ), (all p-values $>0.05$ ). We also found that spirometric measures of distal airway obstruction were not significantly different between these both groups: $\mathrm{FEF}_{25-75}(71 \pm 21$ vs $80 \pm 25, \%)$, FEF50 ( $83 \pm 21$ vs $80 \pm 25$, $\%$ ), (both p-values $>0.05$ ). Interestingly, although all nonspirometric measures of small lung function were elevated in patients with nocturnal asthma: small airway resistance; R5-20 (0.09 \pm 0.10 vs $0.08 \pm 0.07, \mathrm{kPa} / \mathrm{L} / \mathrm{s})$, sReff $(100 \pm 68$ vs $85 \pm 27, \%)$, lung reactance; $\mathrm{X} 5 \mathrm{~Hz}(-0.15 \pm 0.12$ vs -0.13 $\pm 0.05, \mathrm{kPa} / \mathrm{L} / \mathrm{s}) ;$ and $\mathrm{N} 2$ single breath washout $(2.40 \pm 1.46$ vs $1.94 \pm 0.86$, delta/l), (all p-values $>0.05$ ), only measures of LCI and RV reached a statistical significance, LCI (6.7 \pm 0.9 vs $5.9 \pm 0.6, \mathrm{p}<0.01), \mathrm{RV} \% \quad(122 \pm 19$ vs $111 \pm 19$, $\mathrm{p}=0.02$ ), and appeared to be sensitive markers of nocturnal asthma in patients without airflow obstruction, Figure 2. Also in these patients without airflow obstruction, the frequency of nocturnal symptoms, defined by ACT score for nocturnal symptoms, correlated with LCI (Spearman's coefficient $=-0.42, \mathrm{p}<0.001$ ) and RV\% $(-0.32, \mathrm{p}=0.011)$. A principle component analysis (Table 3), that included different lung function measures and the detailed scores for each component of the ACT score, showed that the largest variance between patients 


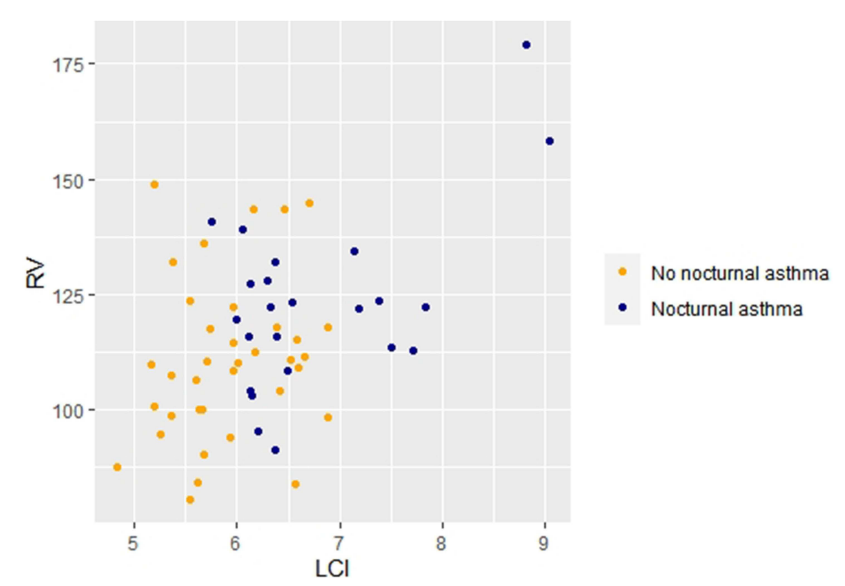

Figure 2 The correlation of nocturnal asthma with air trapping and ventilation heterogeneity in patients without airflow obstruction: A biplot demonstrates a trend of increased air trapping and ventilation heterogeneity in patients with nocturnal asthma, who did not have airflow obstruction based on spirometry. Abbreviations: $\mathrm{LCl}$, lung clearance index; $\mathrm{RV}$, residual volume.

without airflow obstruction is mainly attributable to LCI, $\mathrm{RV} \%$ and the ACT score component of nocturnal symptoms (Table 3). However, the variances of the five ACT score components were comparable, indicating that SAD is related to different symptomatic presentations of asthma and is not specific for nocturnal symptoms.

\section{Discussion}

Our data suggest that nocturnal asthma is closely associated with small airway dysfunction rather than with airflow obstruction. In fact, it appears that small airway dysfunction might contribute to nocturnal asthma independent from the presence of airflow obstruction. Therefore,

Table 3 Principle Component Analysis

\begin{tabular}{|l|c|c|}
\hline Variable & PCI Variances & PC2 Variances \\
\hline LCI & -0.32 & -0.39 \\
RV\% & -0.27 & -0.47 \\
sReff\% & -0.26 & -0.56 \\
FEVI\% & 0.15 & 0.15 \\
ACT-question I & 0.37 & -0.36 \\
ACT-question 2 & 0.38 & -0.17 \\
ACT-question 3 & 0.40 & -0.12 \\
ACT-question 4 & 0.37 & -0.16 \\
ACT-question 5 & 0.39 & -0.29 \\
Proportion of variance & 0.47 & -0.17 \\
Cumulative Proportion & 0.47 & -0.64 \\
\hline
\end{tabular}

Note: The table demonstrates the first two principle components only. Abbreviations: $\mathrm{LCl}$, lung clearance index from multiple breath washout; RV, residual volume; sReff, specific effective airway resistance; FEVI, forced expiratory volume in first second; $\mathrm{PCl}$, first principle components that demonstrates the highest variance among all components. PC2: principle component 2. we propose that the assessment of lung function in asthma should no longer be limited to spirometry alone.

Our data also emphasize that nocturnal asthma is a common disease manifestation that is associated with increased fatigue and has a negative impact on patients' quality of life.

Our study demonstrates a close association between the frequency of nocturnal asthma and the severity of a broad spectrum of distal lung function impairment; such as increased small airway resistance, air trapping, decreased lung elasticity, and ventilation heterogeneity. It is also noteworthy that standard measures of airflow obstruction were comparable between patients with and without nocturnal symptoms. Nocturnal asthma according to our data might therefore be present in patients with the normal conventional pulmonary function test, ie spirometry, as in this subgroup of patients, increased air trapping and ventilation heterogeneity also correlated with the presence and frequency of nocturnal symptoms. The relationship between lung function and nocturnal asthma has been studied previously, particularly in relation to circadian rhythms of lung physiology. ${ }^{24}$ In a pilot study, Rabe and colleagues demonstrated circadian variations in airway responsiveness and airway tone. ${ }^{25}$ Accordingly, it has been suggested that the nocturnal worsening of asthma symptoms results from an exaggerated nighttime decline of the pulmonary expiratory volume or the expiratory flow. ${ }^{26,27}$ Likewise, Kraft and colleagues found that peripheral airway resistance, measured by wedged bronchoscopy at nighttime, was increased in patients with nocturnal asthma compared to patients without nocturnal asthma. ${ }^{7}$ However, data demonstrating the relationship between a broad spectrum of lung function tests that might be performed at daytime as part of routine clinical practice, and nocturnal asthma are limited. In our study, the diagnosis of airflow obstruction alone did not appear to be sufficient in identifying patients with nighttime symptoms or to be the only factor that explains the mechanism by which nocturnal asthma emerges. Here, we show that non-spirometric measures of small airway function are feasible and reproducible tools in identifying patients with increased risk of nocturnal asthma, as they appeared to be more sensitive compared to the conventional spirometry. Additionally, we also demonstrated that the odds of nocturnal asthma increase as the severity of small airway dysfunction increases. Interestingly, we found that nearly half of the patients, who did not have airflow obstruction, had nocturnal asthma, and some of them had even frequent 
night symptoms, which emphasizes the need to involve measures of small airway function in the diagnosis and treatment of symptomatic asthma patients. Moreover, in this subgroup of patients without airflow obstruction, measures of LCI and RV showed the strongest correlation with nocturnal asthma amongst all measures of SAD. While the reason behind this is not fully clear, this might be reflecting that $\mathrm{SAD}$ is rather a spectrum of diverse lung function impairments that correlate differently with the various clinical manifestations of asthma. ${ }^{10}$ An alternative explanation is that the LCI is a universal measure of SAD that indicates the subsequent ventilation heterogeneity caused by multiple lung function impairments, particularly, air trapping. ${ }^{10}$

Mechanistically, the nighttime enhancement of inflammation in the airway has been incriminated in the nocturnal worsening of asthma symptoms and lung function. ${ }^{28-30}$ In a previous study, Kraft and colleagues performed lung biopsies and bronchoalveolar lavage in patients with nocturnal asthma and described an augmented eosinophilic influx in the distal airways compared to proximal airways that were also increased at nighttime compared to daytime. ${ }^{8}$ In line with these findings, newly-diagnosed steroid-naïve patients with nocturnal asthma were found to have higher levels of alveolar nitric oxide than patients without nocturnal asthma. ${ }^{31}$ Our data show that blood or sputum eosinophils and FeNO measures had a tendency to be elevated in patients with frequent nocturnal asthma, however without reaching statistical significance in our analysis. The role of T2-inflammation in nocturnal asthma might have been underestimated in our study, as patients with frequent nocturnal symptoms also had intensified treatment with oral corticosteroids as well as higher doses of inhaled corticosteroids. Nevertheless, there is accumulating evidence about the role of T2-inflammation in small airway dysfunction ${ }^{32,33}$ and the previously described nighttime augmentation of airway inflammation is of particular interest, as it leads to the notion that patients with nocturnal asthma might specifically benefit from therapies targeting T2-inflammation and the small airways. For instance, treatments such as the inhaled extrafine-particle corticosteroid or anti-T2 biological therapies were proposed to improve symptom control and small airway dysfunction in asthma patients. ${ }^{34-36}$

Our study has limitations. First, we did not objectify the nighttime symptoms. However, a questionnaire-based assessment of night symptoms in asthma has been used and validated in previous studies. ${ }^{3,31}$ Second, this is an observational analysis of cross-sectional data. Further interventional studies aiming to improve SAD and associated nocturnal symptoms are warranted to validate our findings. Nevertheless, to the best of our knowledge, this is the first study that found clinically relevant associations of a broad spectrum of distal lung function abnormalities with nocturnal symptoms in asthma.

In summary, nocturnal asthma is still a highly prevalent disease manifestation that adversely affects patients' quality of life. The diagnosis of SAD has clinical relevance in patients with night symptoms, while spirometry should no longer be the solely used lung function test to diagnose and guide treatment in symptomatic asthma patients, as it might underestimate a broad spectrum of distal lung function impairments, which are clearly present in patients with nocturnal asthma.

\section{Abbreviations}

FEV1, forced expiratory volume in first second; LCI, lung clearance index; NA, nocturnal asthma; RV, residual volume; SAD, small airway dysfunction; TLC, total lung capacity.

\section{Data Sharing Statement}

The datasets used during the current study are available from the corresponding author on reasonable request.

\section{Ethics Approval}

The study is a part of the prospective longitudinal All Age Asthma Cohort (ALLIANCE). The study was approved according with the Declaration of Helsinki by the ethics committee at Medical School Luebeck, Germany, and is registered at clinicaltrials.gov (pediatric arm: NCT02496468; adult arm: NCT02419274).

\section{Acknowledgments}

We thank Regine Wieland, Petra Hundack-Winter, Margret Gleiniger, Zaklina Hinz, Susann Prange, Corinna Derwort (LungClinic Grosshansdorf, Grosshansdorf, Germany) for their excellent support in study logistics.

\section{Funding}

The ALLIANCE infrastructure is provided by the participating sites of the German Centre for Lung Research (DZL) and associated study centers and hospitals. Direct costs of the ALLIANCE Cohort are being paid by project grants from the German Federal Ministry of Education and Research (Bundesministerium für Bildung und Forschung, $\mathrm{BMBF}$ ), grant number "82DZL001A4“. 


\section{Disclosure}

Mustafa Abdo reports no conflict of interest. Frederik Trinkmann received travel support from Actelion, Berlin Chemie, Boehringer Ingelheim, Chiesi, Novartis, Mundipharma and TEVA as well as speaker or consultation fees from AstraZeneca, Berlin Chemie, Boehringer Ingelheim, Bristol-Myers Squibb, Chiesi, GlaxoSmithKline, Novartis and Roche, Sanofi aventis, all outside the submitted work. Anne-Marie Kirsten, Heike biller and Frauke Pedersen report no conflict of interest. Erika von Mutius reports personal fees from Pharmaventures, personal fees from OM Pharma S. A., personal fees from Springer-Verlag $\mathrm{GmbH}$, personal fees from Elsevier GmbH and Elsevier Ltd., personal fees from Peptinnovate Ltd., personal fees from Turun Yliopisto, personal fees from Tampereen Yliopisto, personal fees from Helsingin Yliopisto, personal fees from European Respiratory Society, personal fees from Deutsche Pharmazeutische Gesellschaft e. V., personal fees from Massachusetts Medical Society, personal fees from Chinese University of Hongkong, personal fees from European Commission, personal fees from Böhringer Ingelheim International $\mathrm{GmbH}$, personal fees from Universiteit Utrecht, Faculteit Diergeneeskunde, personal fees from Universität Salzburg, personal fees from Georg Thieme Verlag, personal fees from Japanese Society of Pediatric Allergy and Clinical Immunology (JSPACI), outside the submitted work; In addition, Dr. von Mutius has a patent LU101064 - Barn dust extract for the prevention and treatment of diseases pending, a patent EP2361632: Specific environmental bacteria for the protection from and/or the treatment of allergic, chronic inflammatory and/or autoimmune disorders with royalties paid to ProtectImmun $\mathrm{GmbH}$, a patent EP 1411977: Composition containing bacterial antigens used for the prophylaxis and the treatment of allergic diseases licensed to ProtectImmun $\mathrm{GmbH}$, a patent number EP1637147: Stable dust extract for allergy protection licensed to ProtectImmun $\mathrm{GmbH}$, and a patent EP 1964570: Pharmaceutical compound to protect against allergies and inflammatory diseases licensed to ProtectImmun GmbH. Matthias V. Kopp, Gesine Hansen, Benjamin Waschki, Klaus F. Rabe and Henrik Watz reports no relevant conflict of interest. Thomas Bahmer reports grants from BMBF: Unrestricted research grant for the German Center for Lung Research (DZL), during the conduct of the study; personal fees from AstraZeneca, personal fees from GlaxoSmithKline, personal fees from Novartis, and personal fees from Roche, outside the submitted work. The authors report no other conflicts of interest in this work.

\section{References}

1. Lemanske RF, Busse WW. Asthma: clinical expression and molecular mechanisms. J Allergy Clin Immunol. 2010;125(2):S95-S102. doi:10.1016/j.jaci.2009.10.047

2. Turner-Warwick M. Epidemiology of nocturnal asthma. Am J Med. 1988;85(1B):6-8. doi:10.1016/0002-9343(88)90231-8

3. Raherison C, Abouelfath A, Le Gros V, Taytard A, Molimard M. Underdiagnosis of nocturnal symptoms in asthma in general practice. J Asthma. 2006;43(3):199-202. doi:10.1080/0277090060 0566744

4. Greenberg H, Cohen RI. Nocturnal asthma. Curr Opin Pulm Med. 2012;18(1):57-62. doi:10.1097/MCP.0b013e32834d098e

5. Calhoun WJ. Nocturnal asthma. Chest. 2003;123(3 Suppl):399S405S. doi:10.1378/chest.123.3_suppl.399S

6. Sutherland ER. Nocturnal asthma. J Allergy Clin Immunol. 2005;116 (6):1179-86; quiz 1187. doi:10.1016/j.jaci.2005.09.028

7. Kraft M, Pak J, Martin RJ, Kaminsky D, Irvin CG. Distal lung dysfunction at night in nocturnal asthma. Am J Respir Crit Care Med. 2001;163(7):1551-1556. doi:10.1164/ajrccm.163.7.2008013

8. Kraft M, Djukanovic R, Wilson S, Holgate ST, Martin RJ. Alveolar tissue inflammation in asthma. Am J Respir Crit Care Med. 1996;154 (5):1505-1510. doi:10.1164/ajrccm.154.5.8912772

9. Postma DS, Brightling C, Baldi S, et al. Exploring the relevance and extent of small airways dysfunction in asthma (ATLANTIS): baseline data from a prospective cohort study. Lancet Respir Med. 2019;7 (5):402-416. doi:10.1016/S2213-2600(19)30049-9

10. Abdo M, Trinkmann F, Kirsten A-M, et al. Small Airway Dysfunction Links Asthma Severity with Physical Activity and Symptom Control. J Allergy Clin Immunol Pract. 2021. doi:10.1016/j.jaip.2021.04.035

11. Fuchs O, Bahmer T, Weckmann M, et al. The all age asthma cohort (ALLIANCE) - from early beginnings to chronic disease: a longitudinal cohort study. BMC Pulm Med. 2018;18(1):140. doi:10.1186/s12890-018-0705-6

12. Schatz M, Sorkness CA, Li JT, et al. Asthma Control Test: reliability, validity, and responsiveness in patients not previously followed by asthma specialists. J Allergy Clin Immunol. 2006;117(3):549-556. doi:10.1016/j.jaci.2006.01.011

13. Juniper EF, Buist AS, Cox FM, Ferrie PJ, King DR. Validation of a standardized version of the Asthma Quality of Life Questionnaire. Chest. 1999;115(5):1265-1270. doi:10.1378/chest.115.5.1265

14. Smets EM, Garssen B, Bonke B, Haes JCD. The Multidimensional Fatigue Inventory (MFI) psychometric qualities of an instrument to assess fatigue. J Psychosom Res. 1995;39(3):315-325. doi:10.1016/ 0022-3999(94)00125-O

15. Miller MR, Hankinson J, Brusasco V, et al. Standardisation of spirometry. Eur Respir J. 2005;26(2):319-338. doi:10.1183/ 09031936.05.00034805

16. Wanger J, Clausen JL, Coates A, et al. Standardisation of the measurement of lung volumes. Eur Respir J. 2005;26(3):511-522. doi:10.1183/09031936.05.00035005

17. Oostveen E, MacLeod D, Lorino H, et al. The forced oscillation technique in clinical practice: methodology, recommendations and future developments. Eur Respir J. 2003;22(6):1026-1041. doi:10.1183/09031936.03.00089403

18. Robinson PD, Latzin P, Verbanck S, et al. Consensus statement for inert gas washout measurement using multiple- and single- breath tests. Eur Respir J. 2013;41(3):507-522. doi:10.1183/ 09031936.00069712 
19. Quanjer PH, Tammeling GJ, Cotes JE, Pedersen OF, Peslin R, Yernault JC. Lung volumes and forced ventilatory flows. Eur Respir J. 1993;6(Suppl 16):5-40. doi:10.1183/09041950.005s1693

20. Quanjer PH, Stanojevic S, Cole TJ, et al. Multi-ethnic reference values for spirometry for the 3-95-yr age range: the global lung function 2012 equations. Eur Respir J. 2012;40(6):1324-1343. doi:10.1183/09031936.00080312

21. Pedersen F, Zissler UM, Watz H, Rabe KF, Hohlfeld JM, Holz O. Rating sputum cell quality in clinical trials for asthma and COPD treatment. Int J Chron Obstruct Pulmon Dis. 2019;14:195-198. doi:10.2147/COPD.S188033

22. Paggiaro PL, Chanez P, Holz O, et al. Sputum induction. Eur Respir J Suppl. 2002;37:3s-8s. doi:10.1183/09031936.02.00000302

23. Dweik RA, Boggs PB, Erzurum SC, et al. An Official ATS Clinical Practice Guideline: interpretation of Exhaled Nitric Oxide Levels (FeNO) for Clinical Applications. Am J Respir Crit Care Med. 2011;184(5):602-615. doi:10.1164/rccm.9120-11ST

24. Sundar IK, Yao H, Sellix MT, Rahman I. Circadian molecular clock in lung pathophysiology. Am J Physiol Lung Cell Mol Physiol. 2015;309(10):L1056-75. doi:10.1152/ajplung.00152.2015

25. Rabe KF, Jörres R, Nowak D, Behr N, Magnussen H. Comparison of the effects of salmeterol and formoterol on airway tone and responsiveness over 24 hours in bronchial asthma. Am Rev Respir Dis. 1993;147(6 Pt 1):1436-1441. doi:10.1164/ajrccm/147.6_Pt 1.1436

26. Hetzel MR, Clark TJ. Comparison of normal and asthmatic circadian rhythms in peak expiratory flow rate. Thorax. 1980;35(10):732-738. doi:10.1136/thx.35.10.732

27. Martin RJ, Cicutto LC, Ballard RD. Factors related to the nocturnal worsening of asthma. Am Rev Respir Dis. 1990;141(1):33-38. doi:10.1164/ajrccm/141.1.33

28. Calhoun WJ, Bates ME, Schrader L, Sedgwick JB, Busse WW. Characteristics of peripheral blood eosinophils in patients with nocturnal asthma. Am Rev Respir Dis. 1992;145(3):577-581. doi:10.1164/ajrccm/145.3.577
29. Mackay TW, Wallace WA, Howie SE, et al. Role of inflammation in nocturnal asthma. Thorax. 1994;49(3):257-262. doi:10.1136/ thx.49.3.257

30. Postma DS, Oosterhoff Y, van Aalderen WM, Kauffman HF, Wempe JB, Koëter GH. Inflammation in nocturnal asthma? Am J Respir Crit Care Med. 1994;150(5 Pt 2):S83-6. doi:10.1164/ ajrccm/150.5_Pt_2.S83

31. Lehtimäki L, Kankaanranta H, Saarelainen S, Turjanmaa V, Moilanen E. Increased alveolar nitric oxide concentration in asthmatic patients with nocturnal symptoms. Eur Respir J. 2002;20 (4):841-845. doi:10.1183/09031936.02.00202002

32. Hamid Q, Song Y, Kotsimbos TC, et al. Inflammation of small airways in asthma. $J$ Allergy Clin Immunol. 1997;100(1):44-51. doi:10.1016/S0091-6749(97)70193-3

33. Synek M, Beasley R, Frew AJ, et al. Cellular infiltration of the airways in asthma of varying severity. Am J Respir Crit Care Med. 1996;154(1):224-230. doi:10.1164/ajrccm.154.1.8680684

34. Barnes N, Price D, Colice G, et al. Asthma control with extrafine-particle hydrofluoroalkane-beclometasone vs. large-particle chlorofluorocarbon-beclometasone: a real-world observational study. Clin Exp Allergy. 2011;41(11):1521-1532. doi:10.1111/j.13652222.2011.03820.x

35. van der Molen T, Postma DS, Martin RJ, et al. Effectiveness of initiating extrafine-particle versus fine-particle inhaled corticosteroids as asthma therapy in the Netherlands. BMC Pulm Med. 2016;16 (1):80. doi:10.1186/s12890-016-0234-0

36. Abdo M, Watz H, Veith V, et al. Small airway dysfunction as predictor and marker for clinical response to biological therapy in severe eosinophilic asthma: a longitudinal observational study. Respir Res. 2020;21(1):278. doi:10.1186/s12931-020-01543-5

\section{Publish your work in this journal}

The Journal of Asthma and Allergy is an international, peer-reviewed open-access journal publishing original research, reports, editorials and commentaries on the following topics: Asthma; Pulmonary physiology; Asthma related clinical health; Clinical immunology and the immunological basis of disease; Pharmacological interventions and new therapies. The manuscript management system is completely online and includes a very quick and fair peer-review system, which is all easy to use. Visit http://www.dovepress.com/testimonials.php to read real quotes from published authors. 